\title{
Er is (n)iets mis met de maatregel TBS Een overzicht van de recente ontwikkelingen
}

\author{
B.C.M. Raes ${ }^{*}$
}

\section{Een korte terugblik op recente ontwikkelingen}

Voor dit historisch overzicht van de recente ontwikkelingen in de TBS maak ik gebruik van enkele wetswijzigingen en het verschijnen van rapporten als kenmerken en indicatoren voor de richting waarin de tenuitvoerlegging van de maatregel TBS zich in de laatste 10 à 20 jaar ontwikkeld heeft.

Van TBR naar TBS, wetswijziging 1988

De belangrijkste oogmerken van deze wetswijziging waren een nadrukkelijker aandeel van het het proportionaliteitsbeginsel bij het opleggen van de maatregel en de verbetering van de rechtspositieregeling voor TBS-gestelden, vooralsnog in de vorm van een tijdelijke regeling, die naar verwacht werd spoedig maar tenslotte pas veel later een definitieve regeling kreeg in de nieuwe Beginselenwet Verpleging Terbeschikkinggestelden (BVT).

TBS, een bijzondere maatregel, nota 1991

Hierin werden de belangrijkste uitgangspunten en voornemens voor het beleid met betrekking tot de tenuitvoerlegging van de maatregel TBS voor de komende jaren vastgelegd. Alom was men van mening dat deze nota de sector TBS op voorsprong zette ten opzichte van de ontwikkelingen in het gevangeniswezen en de jeugdsector.

TBS en sanctietoepassing geestelijk gestoorde gedetineerden, commissie Fokkens, rapport 1993

De Commissie stelde onder meer voor de TBS met aanwijzingen (die in de praktijk weinig toepassing had gevonden) te veranderen in de TBS met voorwaarden, op grond waarvan de omzetting in een TBS met verpleging

* Dick Raes is bijzonder hoogleraar forensische psychiatrie aan de Vrije Universiteit te Amsterdam 
efficiënter werd geregeld. Ook de voorwaardelijke beëindiging van de TBS werd als nieuwe modaliteit geïntroduceerd. Daarbij werd de verantwoordelijkheid van de TBS-kliniek voor het proefverlof overgedragen aan het toezicht van de reclassering met een daadwerkelijk perspectief op beëindiging van de maatregel. De regering nam het voorstel om tenuitvoerlegging van de maatregel bij combinatievonnissen vooraf te laten gaan aan de gevangenisstraf niet over, maar als tegemoetkoming aan de terzake gevoerde argumentatie werd besloten dat TBS-gestelden na het uitzitten van een derde van hun gevangenisstraf in aanmerking konden komen voor plaatsing in een TBSinrichting.

Doelmatig behandelen, IBO I, 1995

Het is het eerste interdepartementaal beleidsonderzoek financieringssysteem van forensisch psychiatrische hulpverlening. Onder de druk van de toenemende capaciteitsproblemen in de sector TBS werd o.a. voorgesteld te komen tot een betere monitoring van de tenuitvoerlegging op individueel en op geaggregeerd niveau om meer inzicht in en greep op de tenuitvoerlegging van de maatregel TBS en ook op de patient-routing van andere categorieën forensisch psychiatrische patiënten. Dit zou gepaard moeten gaan met een soort persoonsgebonden budget, d.w.z. per individuele patiënt zou een verpleeg- en behandelingsbudget moeten worden vastgesteld, bij overschrijding waarvan de betreffende kliniek zich zou moeten verantwoorden.

Over Stromen, IBO II, 1998

Het tweede interdepartementaal beleidsonderzoek over in-, door- en uitstroom bij de TBS. Ondanks dat de regering de aanbevelingen van het eerstgenoemde interdepartementaal beleidsonderzoek had overgenomen, werd in verband met de "acute" capaciteitsnood (o.a. resulterende in aanzienlijke financiële schadevergoedingen voor TBS-passanten, via civiele procedures afgedwongen vanwege de lange passantentijd, hetgeen uiteraard de politieke druk op de minister van justitie vergrootte om met snelle oplossingen te komen) besloten tot een tweede interdepartementaal beleidsonderzoek. Mede door de samenstelling van deze commissie werd nu een oplossingsrichting gezocht die sterk gebaseerd was op financiële incentives. Als alle TBSklinieken een vergelijkbare populatie zouden hebben, zouden zij afgerekend kunnen worden op de effectiviteit van hun behandeling, d.w.z. de gemiddelde intramurale verblijfsduur in de TBS-inrichtingen. Langdurig verblijf zou tot consequentie hebben dat de dagverpleegprijs aanzienlijk verminderd zou worden. Om een dergelijke competitieachtige marktwerking tot stand te brengen, moet het bestaande selectiesysteem (een van de functies van het Dr. F.S. Meijers Instituut) verdwijnen en zal er een aselecte toewijzing van 
patiënten naar de klinieken plaats vinden. Daarnaast werden een aantal andere aanbevelingen gedaan met betrekking tot de instroom, doorstroom en uitstroom van TBS-gestelden en voor kwaliteitsverbeteringen in de tenuitvoerlegging.

Voort-durend delictgevaarlijke TBS-verpleegden, rapport 1998

van de commissie "Zorg voor voortdurend delictgevaarlijke TBS-verpleegden". Het taboe om het probleem te onderkennen van TBS-gestelden die levenslang in een TBS-inrichting verbleven (met name in de Rijksinrichting Veldzicht) werd doorbroken en in deze rapportage werd het probleem van de voortdurend delictgevaarlijke TBS-gestelden genuanceerd aan de orde gesteld.

Startdocument "Toekomst TBS", 2000

plan van aanpak, met als deelprojecten van het Verbeterproject TBS Terecht: kwaliteitsverbetering, preklinische interventie, plaatsingssystematiek, toegang TBS, veilig oversteken.

"Veilig en Wel", een beleidsvisie op de TBS, commissie Kosto 2001

Hierin werden twee beleidsopties in het verlengde van elkaar voorgesteld. De eerste optie is de bevordering van de circuitvorming tussen de sector TBS en de GGZ ten einde meer door- en uitstroom van TBS-patiënten naar de algemene geestelijke gezondheidszorg te bevorderen en daardoor de sector TBS uit haar isolement t.o.v. de algemene geestelijke gezondheidszorg te bevrijden. De tweede optie om de sector TBS te integreren in de algemene geestelijke gezondheidszorg. Bij dit laatste werden de nodige slagen om de arm gehouden. Immers de minister van justitie moest zijn verantwoordelijkheid ten aanzien van de beveiliging van de maatschappij behouden, terwijl de sector TBS door de integratie met de algemene geestelijke gezondheidszorg inhoudelijk zou moeten profiteren van de verworvenheden van de ontwikkelingen in de algemene geestelijke gezondheidszorg, ressorterend onder de minister van VWS.

\section{Opmerkingen ten aanzien van deze ontwikkelingen}

Dit is enkel een beperkt overzicht van wetswijzigingen en rapporten die van de zijde van het ministerie van justitie verschenen zijn. Daarnaast heeft zich vanaf het begin van de tachtiger jaren een stroom van publicaties en rapporten op de hoofden van de psychisch gestoorde justitiabelen opgestapeld. 
Het zou de moeite waard zijn als iemand de draad van Hofstee's rechtshistorische studie "Van TBR naar TBS" zou oppakken waar hij geëindigd is, juist voor het van kracht worden van de wetswijziging van 1988. En zeker zo interessant zou een sociaal historische studie zijn over de maatregel TBS en haar tenuitvoerlegging tegen het licht van de politiek-maatschappelijke ontwikkelingen.

Het bijzondere karakter van de maatregel TBS is het compromis dat in haar besloten ligt tussen de criminologische politiek gebaseerd op de vergelding, de zogeheten klassieke richting, ook wel het daadgerichte strafrecht genoemd, en de moderne richting, het dadergerichte strafrecht. Het compromiskarakter is tegelijkertijd haar kwetsbaarheid en haar overlevingskracht. In ieder geval is het, historisch beschouwd, de bron voor permanente meer of minder hevige discussies over het bestaansrecht van deze unieke maatregel. Immers, afhankelijk van de tijdgeest, kunnen beide richtingen in het strafrecht zich er in meer of mindere mate zich in vinden.

Even een stelling terzijde : "In onze huidige samenleving die meer dan enkele decennia geleden naar repressie neigt, lijkt het strafrecht (en daarmee ook de maatregel TBS) meer en meer ingezet te worden, niet als sluitstuk, maar als reactief rechtsmiddel als andere rechtsmiddelen of maatschappelijke voorzieningen onvoldoende effect gehad lijken te hebben: fraudebestrijding, calamiteiten, criminaliteit bij etnische minderheden, maar ook de uitstoting van seksueel delinquenten uit de samenleving. Het slachtofferschap lijkt een eigen plaats te claimen in het daad- en/of dadergerichte strafrecht en tegelijkertijd treedt bij schikkingen door het openbaar ministerie een nieuw soort utilitaristische ethiek naar voren. De minister van justitie lijkt zich vaker dan ooit in de Tweede Kamer te moeten verantwoorden vanwege incidenten en structurele maatschappelijke misstanden en wordt gevraagd om maatregelen te treffen met betrekking tot maatschappelijk conflictueus gedrag waar andere wetgeving kennelijk onvoldoende voorziet in heldere voorschriften of in de naleving daarvan.

Zo dreigt in deze context de TBS als maatregel te verworden tot een instrument om mensen langdurig uit de samenleving te verwijderen als ander beleid in onze multiculturele samenleving faalt en als maatregel die mensen verder marginaliseert. Met het verdwijnen van het medisch paternalisme heeft het justitieel kader zich geconfronteerd gezien met maatschappelijk deviant gedrag op basis van psychische stoornissen (o.a. openbare orde problemen) waarvoor vervolgens de inmiddels veranderde GGZ verantwoordelijk wordt gesteld: samen te vatten als een alternerend proces van juridiseren en medicaliseren. Met de oppositie tegen het medisch paternalisme wordt onder andere bedoeld het verdwijnen van het bestwilcriterium en het exclusief toepassen van het gevaarscriterium in het kader van de wet BOPZ. 
De situatie lijkt steeds complexer te worden: De TBS blijkt gezien de voorgeschiedenis van de TBS-gestelden steeds meer de functie van ultimum refugium te worden voor mensen waar de samenleving (en vooral de GGZ) geen raad mee weet, (meer dan 60\% van de TBS-gestelden heeft eerdere contacten gehad met de GGZ voor het tot het TBS-delict kwam). Het aantal gedetineerden met een psychische stoornis neemt toe. De rechter beschikt over een zich uitbreidend arsenaal van mogelijkheden om vonnissen met een bijzondere voorwaarde op te leggen die in de GGZ ten uitvoer moeten worden gebracht. Hierbij dient zich het al eerder door mij gesignaleerde probleem zich aan dat, terwijl de minister van Justitie verantwoordelijk is voor een humane tenuitvoerlegging van sancties, hij in toenemende mate afhankelijk is van de bereidwilligheid van GGZ-voorzieningen, op wiens beleid noch de minister van Justitie, noch de minister van VWS een direct sturende invloed hebben.

\section{Crisis?}

Het bovenstaand overzicht, doelgericht geselecteerd uit een veelheid verschenen rapporten, kan geplaatst worden tegen de werkelijkheid van een aantal ontwikkelingen. In ieder geval zou een algemene conclusie kunnen zijn dat er sprake is van een crisissituatie. Maar de vraag is legitiem: welke factoren waren van invloed op deze crisis?

Tot ongeveer 1980 vormde de sector TBS een tamelijk overzichtelijk stelsel. De $10 \%$ volledig ontoerekeningsvatbaren werden geplaatst in de Rijks Psychiatrische Inrichting in Eindhoven, later: "de Grote Beek" en thans het Forensisch Psychiatrisch Centrum van de GGzE geheten. De verminderd toerekeningsvatbare TBS-gestelden werden geplaatst in het gedifferentieerde aanbod van TBR-klinieken. Vanaf de jaren tachtig traden er ingrijpende veranderingen op in de toenmalige TBR-populatie, zowel in criminologisch opzicht (vooruitlopend op de wetsherziening van 1988: vooral ernstige gewelddadige en sexueel-agressieve delinquenten en het verdwijnen van louter vermogensdelinquenten) als in psychopathologische kenmerken : meer psychotisch gestoorde delinquenten, waarbij de stoornis vaak gepaard ging met persoonlijkheidsstoornissen en afhankelijkheid van psycho-actieve stoffen.

De TBS-inrichtingen hebben op deze veranderingen als het ware marktvolgend - d.w.z. zonder centrale sturing - gereageerd door hun opnamebeleid en hun zorgaanbod hieraan aan te passen, hiermee zowel in kwalitatief als in kwantitatief opzicht brekend met de tot dan toe heersende traditie. Als voorbeeld hiervoor mag gelden dat tot deze periode voor de maximale capaciteit van TBS-klinieken een aantal van 80 tot 90 plaatsen als heilig gold wilde 
men het geheel van de behandelingsorganisatie consistent georiënteerd houden op dezelfde uitgangspunten. Met name de rijksinrichtingen werden op grond van de capaciteitsnood uitgebreid, soms met het dubbele van het aantal oorspronkelelijke plaatsen. Men kan zich voorstellen dat dit niet zonder slag of stoot gepaard ging. Maar ook de particuliere TBS-klinieken pasten hun ideologische uitgangspunten aan door afdelingen voor psychotische TBS-gestelden te openen, die een benadering behoefden die strijdig was met de traditionele uitgangspunten van de kliniek.

Bij het verschijnen van de nota $T B S$, een bijzondere maatregel leek alles nog onder controle, men voorzag problemen, maar daarop werd in de nota geanticipeerd. In wezen kan het rapport "Doelmatig Behandelen" gezien worden in het verlengde van de nota TBS: het is een visie op inhoudelijke en capacitaire ontwikkelingen. Het met name van af 1994 dramatisch manifest geworden capaciteitsprobleem ligt ten grondslag aan alle rapporten die daarna verschenen zijn. Het probleem werd derhalve terug gebracht tot een planningsprobleem en gezien de omvang tot een financieel probleem en vervolgens tot een bestuurlijk en politiek probleem. Ook in het rapport van de commissie Kosto wordt het bestaansrecht van de maatregel TBS nadrukkelijk niet ter discussie gesteld, maar het is de vraag of dit stellig standpunt niet impliciet juist wel het bestaansrecht op de helling zet. Recent pleitte het kamerlid Dittrich voor een TBS-systeem dat enkel toegankelijk zou moeten zijn voor volledig ontoerekeningsvatbaren.

Ten opzichte van het ministerie van Justitie bevonden met name de particuliere TBS-inrichingen zich in een bijzondere positie omdat de schaarste aan TBS-plaatsen primair de verantwoordelijkheid van het ministerie van Justitie betrof en niet de verantwoordelijkheid van de (uitvoerende) sector van TBS-klinieken. De druk waarmee de benodigde capaciteitsuitbreiding gepaard ging kwam dan ook hoofdzakelijk terecht op de rijks-TBSinrichtingen, die immers een meer directe bestuurlijke relatie hebben met het ministerie van justitie dan de particuliere (niet) justitiele TBS-inrichtingen.

Het is in de lijn van deze ontwikkelingen dan ook niet verbazingwekkend dat het probleem van de voortdurend-delictgevaarlijke TBS-gestelden in openheid aan de orde gesteld kon worden. Het fenomeen als zodanig bestond al lang. Ter illustratie kan dienen het TBS-kerkhof van de Rijksinrichting Veldzicht. Het valt haast niet te ontkennen dat het in meerdere opzichten ingewikkelde inhoudelijke probleem van de voortdurend-delictgevaarlijke (therapie-resistente) TBS-gestelden een rol ging spelen in het voorgestelde beleid met betrekking tot output-financiering, d.w.z. dat na een intramuraal verblijf van zes jaar de dagverpleegprijs drastisch wordt verminderd. Door de vermenging van twee verschillende problemen, te weten het capaciteitsprobleem en de daarop gebaseerde financiële "incentives" (output- 
financiering) en het fenomeen van de voortdurend delictgevaarlijke TBSgestelden, ontstaat het risico van een tweedeling in "kansrijke en kansarme" TBS-gestelden. Het behoeft geen nadere uitleg dat hierdoor het risico tot bestempeling met het etiket "voortdurend-delictgevaarlijk" vanuit het oogpunt van het management van de TBS-inrichtingen een zekere aantrekkelijkheid krijgt.

\section{Andere factoren}

Daarnaast zijn er factoren te onderkennen die als zodanig niet direct met de juridische uitgangspunten van de maatregel TBS van doen hebben :

De kennelijke behoefte aan een aanzienlijke uitbreiding van de celcapaciteit - slechts ten dele als gevolg van het opleggen van langere vrijheidsbenemende straffen - heeft met zich meegebracht dat ook meer justitiabelen met een psychische stoornis in detentie terecht kwamen, met als gevolg dat op het versoberde detentie-regiem (werkzame detentie) noodzakelijkerwijs meer vormen van regiem-differentiatie volgden (individuele begeleidingsen bijzondere zorgafdelingen).

De populatie TBS-gestelden veranderde in de aanloop naar de wetswijziging van 1988 aanzienlijk: zowel wat betreft hun TBS-delicten (vermogensdelinquenten maakten plaats voor vrijwel uitsluitend gewelds- en agressief sexuele delinquenten), hun psychopathologische kenmerken wezen op een toename van het aantal psychotici (met name onder allochtone TBS-gestelden) en verslaving aan drugs bleek -evenals in de algemene GGZ- de behandeling te compliceren. De TBS-sector heeft hierop gereageerd met aanpassingen in haar traditionele behandelingsaanbod. Het ministerie zocht een antwoord op de capaciteitsproblemen o.a. in drastische uitbreidingen van met name de rijks-TBS-inrichtingen, waarmee het voorheen als vaststaand beginsel dat een TBS-kliniek de omvang van maximaal 80-90 plaatsen niet mocht overschrijden om een consistente behandelingsorganisatie mogelijk te maken, bijna gedachteloos overboord gezet werd. Velen wijzen de vermaatschappelijking van de psychiatrische zorg aan als een van de oorzaken van het toegenomen aantal psychotici in de TBS (wegvallen van de asylfunctie van de APZ-en) alsook het strict toepassen van het gevaarscriterium ten koste van het bestwilcriterium bij onvrijwillige opnamen in de GGZ. De gemiddelde intramurale verblijfsduur nam steeds verder toe en het aantal beëindigingen van de TBS bleef steeds verder achter bij het aantal opleggingen. 


\section{Enkele reacties}

De politiek reageerde op verschillende wijzen: enerzijds werd de maatregel vooral de betekenis gegeven om gevaarlijke mensen met een psychische stoornis zolang mogelijk uit de maatschappij te weren of onder controle te houden, anderzijds werd gevraagd om verkorting van de intramurale verblijfsduur en vermindering van de recidive.

De effecten van de voorstellen van IBO II (aselecte toewijzing van TBSgestelden aan de klinieken, gepaard met output financiering) zullen pas over vele jaren merkbaar zijn, als ze al op zullen treden.

O.a. door de toenmalige Centrale Raad voor Strafrechttoepassing zijn hiertegen ernstige bezwaren gemaakt.

Het ministerie heeft, zoals gezegd - gekozen voor een vereenvoudigde landelijke plaatsingssystematiek en tegelijkertijd wil het door het stimuleren van regionale forensisch psychiatrische circuitvorming in samenhang met de regionale GGZ-voorzieningen de uit- en doorstroom van TBS-gestelden bevorderen.

Opnieuw worden er pleidooien gehouden om de maatregel TBS op te heffen en meer geld te investeren in op te richten behandelgevangenissen. ${ }^{1}$

Veel aandacht wordt besteed aan de ontwikkeling en toepassing van instrumenten voor risicotaxatie om de predictie van toekomstig gevaar meer betrouwbaar te maken met o.a. het risico dat risk assessment gebruikt zal worden ter rechtvaardiging van longstay-afdelingen.

\section{Tenslotte}

Als er iets mis is met de TBS dan is dat in geen geval de maatregel zelf maar wel met de aansturing. Het behandelcircuit is een veld dat autonomie wil behouden en een machtspositie inneemt op grond van de schaarste, en dat zo heterogeen is dat eenduidige aansturing op zich zelf al uiterst gecompliceerd is, rijks- en particuliere justitiële TBS-inrichtingen, niet-justitiële TBS-inrichtingen, andere forensisch psychiatrische voorzieningen elk met geheel andere erkennings- financierings- en sturingscondities.

Mijn conclusie kan dan ook niet anders zijn dat er niets mis is met de maatregel TBS of met haar bestaansrecht, maar dat de aansturing van de tenuit-

${ }^{1}$ Prof. mr J. de Hullu heeft in zijn preadvies voor de Nederlandse Juristenvereniging 2002 het standpunt ingenomen dat de TBS zou moeten integreren in de gevangenisstraf, waarmee hij bedoelt dat de TBS als maatregel kan worden afgeschaft (noot van de red.). 
voerlegging van de maatregel TBS in een crisis geraakt is en dat er dus sprake is van een bestuurlijke crisis. De crisis is des te lastiger omdat zij in toenemende mate de verantwoordelijkheid van twee verschillende departementen betreft.

Daarnaast blijft het natuurlijk de dringende verantwoordelijkheid van de forensische professionals om meer inzicht te verwerven in de vraag - simpel gezegd - wat werkt bij wie? Door het ontbreken van een samenhangend onderzoek naar deze vraag door de sector zelf zou misschien eveneens gesproken kunnen worden van een professionele crisis. 